\title{
Beyond the frontiers of neuronal types: fuzzy classification of interneurons
}

\author{
Harold W Gutch ${ }^{1,2,3^{*}}$, Demian Battaglia ${ }^{1,2}$, Anastassios Karagiannis ${ }^{4,5}$, Thierry Gallopin ${ }^{6}$, Bruno Cauli ${ }^{4}$ \\ From Twenty Second Annual Computational Neuroscience Meeting: CNS*2013 \\ Paris, France. 13-18 July 2013
}

Cortical neurons and, particularly, inhibitory interneurons display a large diversity of morphological, synaptic, electrophysiological, and molecular properties, as well as diverse embryonic origins. Various authors have proposed alternative classification schemes that rely on the concomitant observation of several multimodal features. However, a broad variability is generally observed even among cells that are grouped into a same class. Furthermore, the attribution of specific neurons to a single defined class is often difficult, because individual properties vary in a highly graded fashion, suggestive of continua of features between types. Going beyond the description of representative traits of distinct classes, we focus here on the analysis of atypical cells[1]. We introduce a novel paradigm for neuronal type classification, assuming explicitly the existence of a structured continuum of diversity. Our approach, grounded on the theory of fuzzy sets[2], identifies a small optimal number of model archetypes[3]. At the same time, it quantifies the degree of similarity between these archetypes and each considered neuron. This allows highlighting archetypal cells, which bear a clear similarity to a single model archetype, and edge cells, which manifest a convergence of traits from multiple archetypes.

A ready-to-use software package allowing classification of neuronal data with standard tools (MATLAB, Python, ...) via this fuzzy clustering approach without the need for a reimplementation of the algorithmic aspects is in preparation.

\section{Acknowledgements}

We acknowledge financial support by the German Federal Ministry of Education and Research (BMBF) via the Bernstein Center for Computational Neuroscience Göttingen (01GQ1005B), by the Human Frontier Science Program (RGY0070/2007) and by the Agence Nationale pour la Recherche

\footnotetext{
* Correspondence: harold.gutch@ds.mpg.de

'Department of Nonlinear Dynamics, Max Planck Institute for Dynamics and Self-Organization (MPIDS), Göttingen, Germany

Full list of author information is available at the end of the article
}

(ANR 2011 MALZ 003 01). Anastassios Karagiannis was supported by a Fondation pour la Recherche Médicale fellowship (FDT20100920106).

\section{Author details}

'Department of Nonlinear Dynamics, Max Planck Institute for Dynamics and Self-Organization (MPIDS), Göttingen, Germany. ${ }^{2}$ Bernstein Center for Computational Neuroscience, Göttingen, Germany. ${ }^{3}$ Department of Mathematics, Technische Universität München, Garching, Germany. ${ }^{4} \mathrm{CNRS}$ UMR 7102, Laboratoire de Neurobiologie des processus adaptatifs, Université Pierre et Marie Curie, Paris, France. ${ }^{5}$ Neuroscience, Physiology and Pharmacology, Division of Biosciences, University College London, London, UK. ${ }^{6}$ CNRS UMR 7637, Laboratoire de Neurobiologie et Diversité Cellulaire, ESPCI ParisTech, Paris, France.

Published: 8 July 2013

\section{References}

1. Karagiannis A, Gallopin T, Dávid C, Battaglia D, Geoffroy H, Rossier J, Hillman EM, Staiger JF, Cauli B: Classification of NPY-expressing neocortical interneurons. J Neurosci 2009, 29(11):3642-3659, DOl: 10.1523/ jneurosci.0058-09.2009.

2. Zadeh LA: Fuzzy sets. Inform Control 1965, 8:338-353.

3. Battaglia D, Karagiannis A, Gallopin T, Gutch HW, Cauli B: Beyond the frontiers of neuronal types. Front Neural Circuits 2013, 7:13, DOI: 10.3389/ fncir.2013.00013.

doi:10.1186/1471-2202-14-S1-P56

Cite this article as: Gutch et al:: Beyond the frontiers of neuronal types: fuzzy classification of interneurons. BMC Neuroscience 2013 14(Suppl 1): P56.

Submit your next manuscript to BioMed Central and take full advantage of:

- Convenient online submission

- Thorough peer review

- No space constraints or color figure charges

- Immediate publication on acceptance

- Inclusion in PubMed, CAS, Scopus and Google Scholar

- Research which is freely available for redistribution 